\title{
MECHANICAL CHARACTERISTICS AND WEAR RESISTANCE OF THE CLADDING LAYERS OBTAINED BY MELTING OF CORED WIRES WITH SIMULTANEOUS VIBRATION OF SUBSTRATE
}

\author{
STUDENT Mykhailo1, VOJTOVYCH Andriy², POKHMURSKA Hanna², \\ MARUSCHAK Olena ${ }^{3}$, STUDENT Oleksandra ${ }^{1}$, MARUSCHAK Pavlo ${ }^{4}$ \\ ${ }^{1}$ Karpenko Physico-Mechanical Institute of the National Academy of Sciences of Ukraine, 79060 Lviv, Ukraine \\ ${ }^{2}$ Department of Welding Manufacture, Diagnostics and Restoration of Metal Structures, Lviv Polytechnic \\ National University, 79000, Lviv, Ukraine \\ ${ }^{3}$ Ivano-Frankivsk National Technical University of Oil and Gas, Ivano-Frankivsk, Ukraine \\ ${ }^{4}$ Department of Industrial Automation, Ternopil National Ivan Pul'uj Technical University, Rus'ka str. 56, \\ 46001, Ternopil, Ukraine; e-mail: maruschak.tu.edu@gmail.com
}

\begin{abstract}
A wear proof layer was obtained by applying vibration with a frequency of $100 \mathrm{~Hz}$ and amplitude of 0; $70 ; 300 \mu \mathrm{m}$ to the cored wire of Fe-Cr-B-C doping system during welding. It was shown that horizontal vibration affects the grinding process of boride inclusions: their average diameter reduces from 175 to $5 \mu \mathrm{m}$, and the amount of $(\mathrm{FeCr})_{2} \mathrm{~B}$ plastic phases increases during the redistribution of phases. Wear resistance of the metal, which was deposited using horizontal vibration with an amplitude of $300 \mu \mathrm{m}$, increases by 2.3-2.5 times due to wear with the fixed and unfixed abrasive material, and by 2.8 times due to wear under impact loads. For restoration and strengthening of large-size parts, it is proposed to add Al-Mg powder ( $\mathrm{Al}=47-53 \%, \mathrm{Mg}=53-47 \%$ wt. $\%)$ to the $\mathrm{CW}$ charge to increase wear resistance of the deposited metal of the Fe-Cr-B-C system. This contributes to the dispersion of the boride inclusions, the average diameter of which decreases from 70 to $5 \mu \mathrm{m}$. In the structure of the deposited metal of the Fe-Cr-B-C system, inclusions of the complex alloyed nitrides are extricated with an average size less than $1.0 \mu \mathrm{m}$. As a result, the average value of microhardness increases from 700 to $900 \mathrm{HV}$. Wear resistance of the deposited metal increases by 1.5 times due to wear with the fixed and unfixed abrasive material, and by 2.0 times due to wear under impact loads.
\end{abstract}

KEYWORDS: submerge arc welding, vibration of substrate, deposited metal structure, borides morphology, wear resistance.

\section{Introduction}

Abrasive wear under impact loads is considered one of the most common types of wear. Elements of an excavator (teeth, bucket, body), food grinders and other equipment are operated under such conditions. In the world practice, to protect the surface of structural elements from wear, the deposition of the cored wire $(\mathrm{CW})$ of the Fe-Cr-B-C doping system is used. Most often it is the $\mathrm{CW}$ of the $\mathrm{Fe}-\mathrm{Cr}-\mathrm{B}-\mathrm{C}-\mathrm{V}-\mathrm{W}$ system with refractory carbides or expensive elements (vanadium, niobium, molybdenum, tungsten), as well as rare-earth metals (cerium, lanthanum) added, which contributes to the shredding of the structural components in the welded metal. Due to the dispersion of structural components, the wear resistance of the metal increases, however, the cost of repair also increases significantly due to a high cost of consumables [1-5].

In Ukraine, for the restoration of worn-out surfaces by cladding, the $\mathrm{CW}$ of $\mathrm{Fe}-\mathrm{Cr}-\mathrm{B}-\mathrm{C}$ systems is used. Such cored wires have a low cost, and the deposited metal has a satisfactory wear resistance. However, the main disadvantages of layers obtained by melting of such CW are dendrites of the first and second order with needle-like morphology. Sharp peaks of the solid phase serve as stress concentrators, from which the cracking of the deposited metal begins, followed by its crumble under impact loading [6-9]. 
It is known that the formation of rounded reinforcing phases reduces the stress concentration in the deposited layer, due to which its wear resistance increases. In this paper, it is proposed to disperse structural components in the deposited metal by applying the molten metal to the surface under the influence of mechanical vibration. This is especially useful for the production of bimetallic wear-resistant plates by cladding. In case of large-sized parts, it is proposed to disperse the structural components in the weld metal by modifying the $\mathrm{CW}$ of $\mathrm{Fe}-\mathrm{Cr}-\mathrm{B}-\mathrm{C}$ system due to the $\mathrm{Al}-\mathrm{Mg}$ powder $(\mathrm{Al}=47-53 \%, \mathrm{Mg}=53-47 \%$ wt. $\%)$ added to its content.

\section{Materials and test methods}

The CW with diameter of $3.2 \mathrm{~mm}$ was used to form the cladding metal (Fig. 1). The shell of the $\mathrm{CW}$ was made from low carbon steel $08 \mathrm{kp}(\mathrm{C}=0.05-0.12 ; \mathrm{Si} \leq 0.03 ; \mathrm{Mn}=0.25-0.5 ; \mathrm{Ni} \leq$ $0.3 ; \mathrm{Cr} \leq 0.1 ; \mathrm{Cu} \leq 0.1 ; \mathrm{S} \leq 0.04 ; \leq 0.035)$ and filled with a powder charge based on ferroalloys.

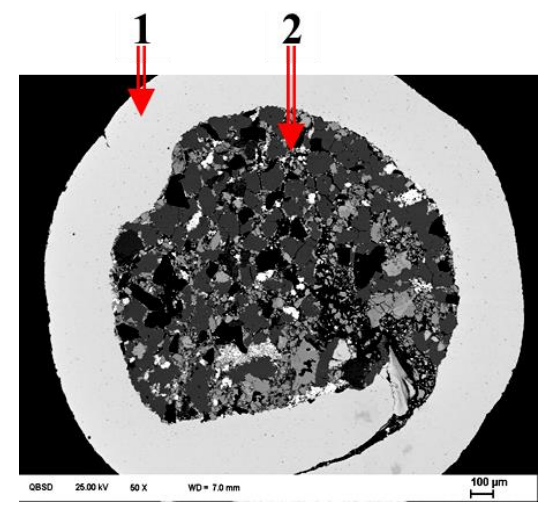

Fig. 1. Cross section CW: 1 - steel shell; 2 - powder charge.

The wires, which form a ferrite and austenitic matrix in the cladding metals, have been selected for the study. In the deposited layers based on a ferrite matrix, there are no structural transformations under abrasive wear and impact loading conditions.

Chemical composition of the CW (table 1) contains a large amount of chromium, boron, which affects positively the wear resistance of the cladding metal, since solid borides are formed in the structure.

Table 1. Chemical composition of the CW charge, wt \%

\begin{tabular}{|c|c|c|c|c|c|c|c|c|c|}
\hline $\mathrm{CW}$ & $\mathrm{C}$ & $\mathrm{B}$ & $\mathrm{Cr}$ & $\mathrm{Ti}$ & $\mathrm{Mn}$ & $\mathrm{Al}$ & $\mathrm{Mg}$ & $\mathrm{Si}$ & $\mathrm{Fe}$ \\
\hline $\begin{array}{c}\text { Cr10B3Mn2Si } \\
\text { (ferrite matrix) }\end{array}$ & 0.08 & 3.5 & 10.0 & - & 2,0 & - & - & 1.0 & \\
\hline $\begin{array}{c}\text { 80Cr20B3Ti } \\
\text { (austenitic matrix) }\end{array}$ & 0.8 & 3.0 & 20,0 & 1.0 & - & - & - & - & Rest \\
\hline $\begin{array}{c}\text { 80Cr20B3TiAlMg } \\
\text { (austenitic matrix) }\end{array}$ & 0.8 & 3.0 & 20,0 & 1.0 & - & 1.0 & 0.5 & - & \\
\hline
\end{tabular}

The addition of the Al-Mg powder to the charge of the cored wire causes the formation of the dispersed magnesium oxide in the welding bath during the cladding process, which affects the dispersion of structural components, as well as the strengthening of the deposited layer. To deposit metal by cored wires, a universal welding automate ABS hanging head was used (Ukraine), and the PSO 500 generator (welding converters PSO-500, Ukraine) as a power source. During cladding, the OSTs $45\left(\mathrm{SiO}_{2}=38.0-44.0 \% ; \mathrm{Mn}=38.0-44.0 \% ; \mathrm{CaO}<6.5 \%\right.$; $\left.\mathrm{MgO}<2.5 \% ; \mathrm{Al}_{2} \mathrm{O}_{3}<5.0 \% ; \mathrm{Fe}_{2} \mathrm{O}_{3}<2.0 \% ; \mathrm{S}<0.15 \% ; \mathrm{P}<0.15 \%\right)$ flux for welding was used to protect against atmospheric effect. The cladding layer was applied twice to a metal substrate from steel St3sp (ASTM A29 / A29M United States) with dimensions $150 \times 300 \mathrm{~mm}$. Vibration treatment of the bath from molten metal in the arc combustion zone was performed 
at a frequency of the substrate oscillations of $100 \mathrm{~Hz}$ and amplitudes of $0,70,300 \mu \mathrm{m}$. Vertical and horizontal vibrations were used. A general view of the used equipment is shown in Fig. 2.

The microstructure of the deposited layers is investigated on a cross-section using the electron microscope EVO 40 XVP. Measurement of hardness is performed on a hardness tester PMT-3 with weight gain of $200 \mathrm{~g}$.

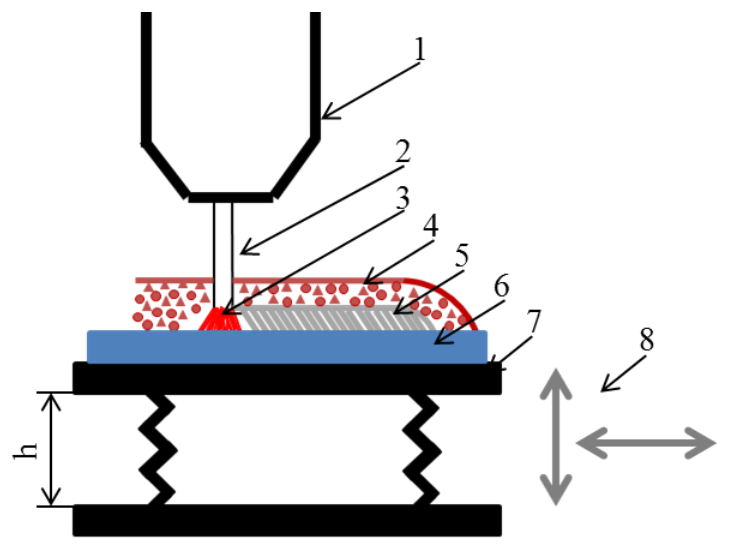

Fig. 2. The scheme of cladding: 1 - torch, 2 - cored wire, 3 - welding arc, 4 - weld flux, 5,

6 - melted and base metals, 7 - vibration stand, 8 - possible direction of vibration, $h$ - amplitude of vibration.

Wear resistance of cladded layers was investigated under different wear conditions. Abrasive wear with a free (unfixed) abrasive material was evaluated according to GOST 23.208-79 (Fig. 3). Dried quartz sand with particle size from 200 to $1000 \mu \mathrm{m}$ was continuously fed into the contact area of the rubber disc and the specimen. The disk rotation speed was $25(\mathrm{~m} / \mathrm{s})$, and the force of its clamping to the specimen was $2.4(\mathrm{kN})$. To evaluate wear with the fixed abrasive material (Fig. 4), abrasive wheel CM-2 on a ceramic bundle was used. Linear friction speed was $0.4(\mathrm{~m} / \mathrm{s})$, the load in the zone of linear contact was $1.5(\mathrm{kN})$.

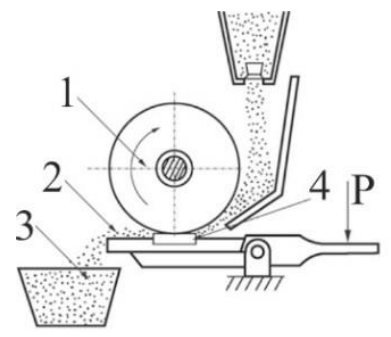

Fig. 3. Scheme of the stand for the study of abrasive wear: 1 - rubber disk, 2 - sand, 3 - capacity

for abrasive material, 4 - sample.
2

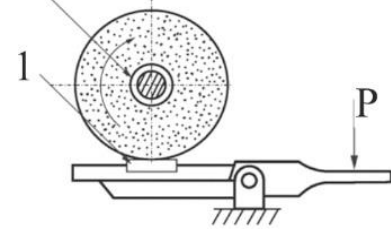

Fig. 4. Scheme of the stand for the study of abrasive wear with fixed abrasive wheel:

1 - sample, 2 - abrasive wheel.

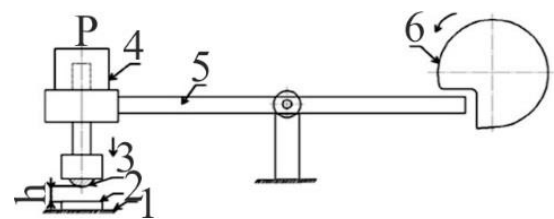

Fig. 5. Scheme of the stand for the study of impact wear: 1 - base, 2 - sample; 3 - indenter, 4 - lash, 5 - arm, 6 - eccentric, $h$ - distance from sample $10 \mathrm{~mm}$.

Impact wear (Fig. 3) was estimated by the impact energy of $12 \mathrm{KJ}$ produced by a ball with diameter of $\varnothing 25 \mathrm{~mm}$ made of steel ShKh15, which fell on the investigated surface with a frequency of $40 \mathrm{~s}^{-1}$. The duration of the experiment was $3600 \mathrm{~s}$. The mass loss of specimens was determined with the accuracy up to $2 \times 10^{-4} \mathrm{~g}$ on an electronic scale. Abrasion resistance under dry friction in the air and in the environment of emulsol was provided using the machine of reversible movement at a load of $300 \mathrm{~g}$ and the experiment time of $2.0 \mathrm{~h}$. The shape of the cross-section of friction tracks was determined using DEKTAK II (Bruker AXS, Germany) 


\section{The structure of the welded metal.}

The phase analysis was performed on the BRUKER D8 DISCOVER X-ray diffractometer. Using phase analysis it was established that the metal deposited without vibration consists of a ferrite matrix doped with chromium and boride inclusions $(\mathrm{FeCr}) \mathrm{B},(\mathrm{FeCr})_{2} \mathrm{~B}$. From literary sources it is known that the $(\mathrm{FeCr})_{2} \mathrm{~B}$ phase contains less chromium and boron than $(\mathrm{FeCr}) \mathrm{B}$ phase, and it is characterized by lower hardness, but it has significantly higher plasticity.

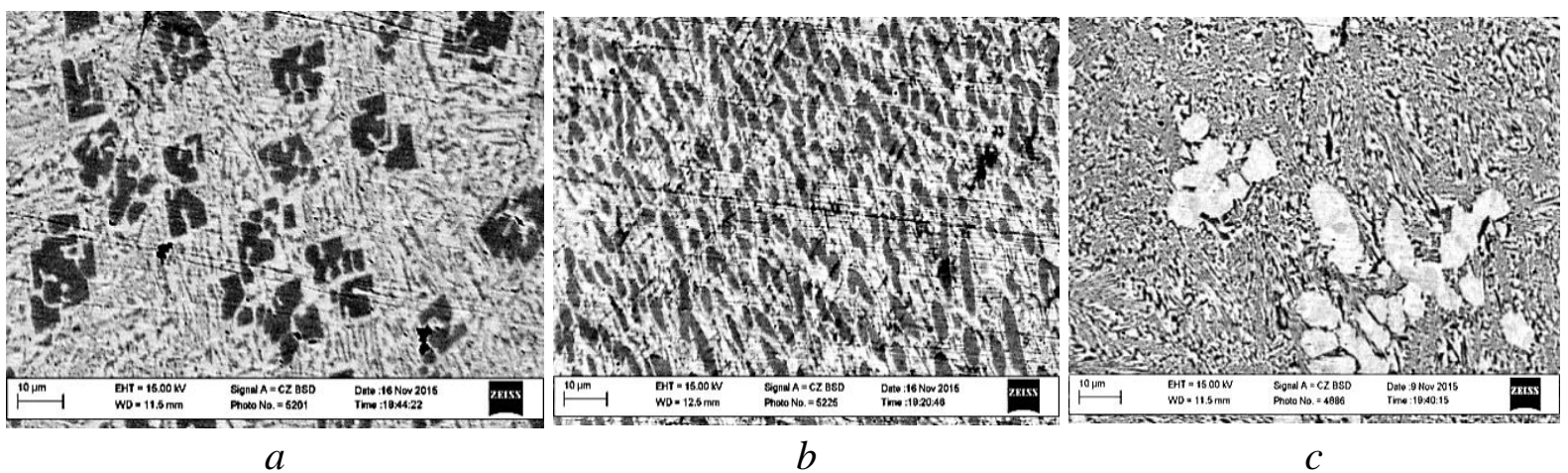

Fig. 6. Microstructure on the crest of metal rollers deposited with CW Cr10B3Mn2Si without $(a)$ and with vertical $(b)$ and horizontal $(c)$ vibration with an amplitude of $300 \mu \mathrm{m}$.

The location of inclusions $(\mathrm{FeCr}) \mathrm{B},(\mathrm{FeCr})_{2} \mathrm{~B}$ in the structure of the weld metal was identified by transmission microspectral analysis on the slabs, and it was found that the inclusions of borides of type $(\mathrm{FeCr}) \mathrm{B}$ are large in size and darker in color, borides of type $(\mathrm{FeCr})_{2} \mathrm{~B}$ are much smaller and lighter (Fig. 6). It was established that grinding of the components in the structure of the deposited metal depends on the direction (vertical or horizontal) and on the amplitude of the substrate vibration. In particular, the dispersion of boride inclusions $(\mathrm{FeCr}) \mathrm{B},(\mathrm{FeCr})_{2} \mathrm{~B}$ increases with an increase in the amplitude of vibration both in vertical and horizontal directions.

In the deposited layers obtained with the overlay of vertical or horizontal vibration with the amplitude of $300 \mu \mathrm{m}$, borides (FeCr)B were shredded, and their sharp-edged shape was smoothed out (Fig. $6 b, c$ ). In this case, the maximum effect of their dispersion is revealed under the horizontal vibration (Fig. $1 \mathrm{c}$ ). The average size of boride inclusions was determined using software AxioVisio 4.6.3 (Carl Zeiss, Germany). In the initial metal of SW Cr10B3Mn2Si with no vibration applied during surfacing, the average size of the boride inclusions $(\mathrm{FeCr}) \mathrm{B}$, $(\mathrm{FeCr})_{2} \mathrm{~B}$ in the structure of the roller crests varied from 10 to $150 \mu \mathrm{m}$, and in the area of their overlap - from 50 to $350 \mu \mathrm{m}$ (Fig. 7 a).

In case of applying both vertical and horizontal vibration during surfacing, the scatter of sizes of borides inclusions $(\mathrm{FeCr}) \mathrm{B},(\mathrm{FeCr})_{2} \mathrm{~B}$ decreases $(\mathrm{Fig} .7 \mathrm{~b}$ ). In particular, for vertical vibration with an amplitude of $70 \mu \mathrm{m}$, it decreased by a factor of 3 , and with an amplitude of $300 \mu \mathrm{m}$ - by 6 times, as compared to their size in a metal deposited without vibration. For horizontal vibration with amplitudes of 70 and $300 \mu \mathrm{m}$, even stronger dispersion was achieved, with the average size of borides $(\mathrm{FeCr}) \mathrm{B},(\mathrm{FeCr})_{2} \mathrm{~B}$ reduced by 10 and 18 times, respectively. Vibration does not only affect the size and shape of the borides, but also the homogeneity of the deposited metal.

To compare two cases with and without vibration, distribution of chromium in the ferrite matrix was used, which is another proof of the vibration effect on the dispersion of borides $(\mathrm{FeCr}) \mathrm{B},(\mathrm{FeCr})_{2} \mathrm{~B}$ (Fig. $8 \mathrm{a}$ ). The width of the zone with a high content of chromium determines the size of the boride inclusions, and the width of zones with a high content of iron 
corresponds to the distances between the borides. When vertical vibration with an amplitude of $300 \mu \mathrm{m}$ was applied, the width of the peaks decreases, and their density increases by 2.4 times. For horizontal vibration with an amplitude of $300 \mu \mathrm{m}$ in the weld metal, the most dispersed borides were $(\mathrm{FeCr})_{2} \mathrm{~B}$, the average size of which was $5 \mu \mathrm{m}$, as evidenced by the distribution of chromium. The results obtained give grounds to assert that the horizontal vibration substantially disperses the structural components of the metal deposited with $\mathrm{CW} \mathrm{Cr} 10 \mathrm{~B} 3 \mathrm{Mn} 2 \mathrm{Si}$. It is checked on the structure of metal deposited with CW 80Cr20B3Ti with amplitudes of the substrate oscillations of 70,200 and $300 \mu \mathrm{m}$. It was found that in this case, the structural components of the deposited metal (boride inclusions) were substantially shredded with an increase in the amplitude of vibration during the surfacing (Fig. 9).
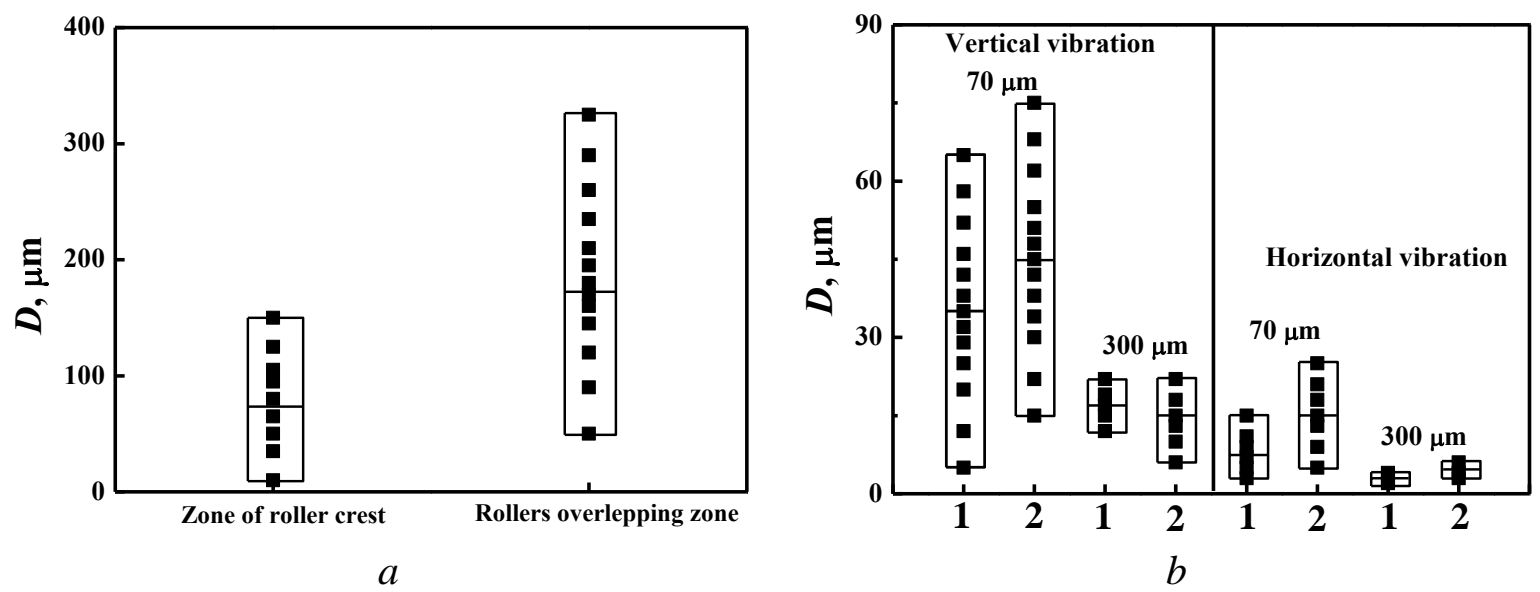

Fig. 7. Average sizes of the boride inclusions $D$ on different specimens with cladding obtained by melting of the $\mathrm{CW}$ Cr10B3Mn2Si without vibration $(a)$ or with vertical and horizontal vibration $(b): 1,2$ - the values at the crest and in the area of roller overlap.
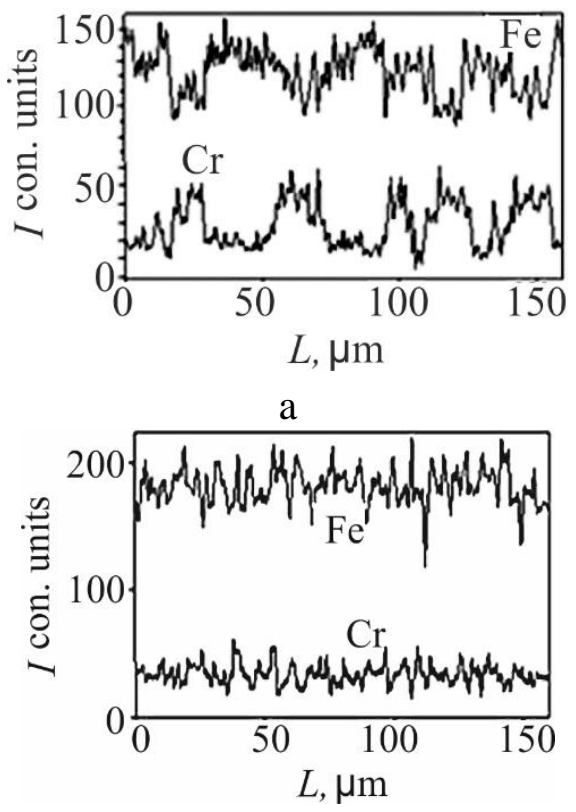

C

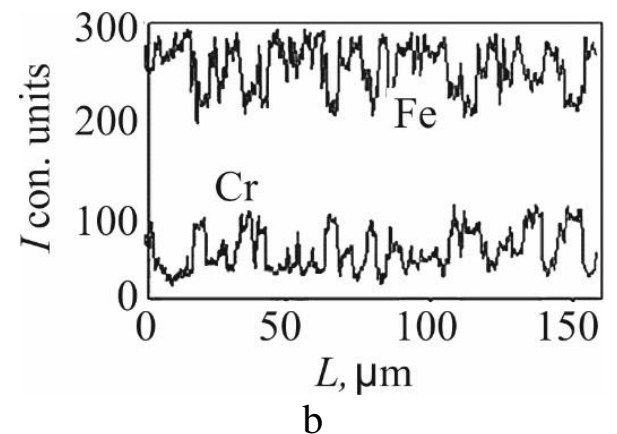

Fig. 8. Distribution of chromium and iron on a segment $L$ of $150 \mu \mathrm{m}$ in metal, cladded by melting of the $\mathrm{CW}$

Cr10B3Mn2Si without (a) and with vertical (b) and horizontal (c) vibrations with an amplitude of $300 \mu \mathrm{m}$. 


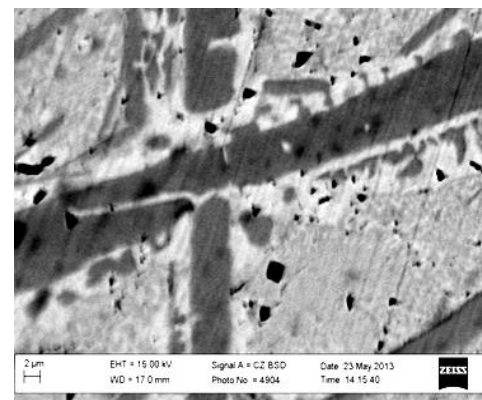

$a$

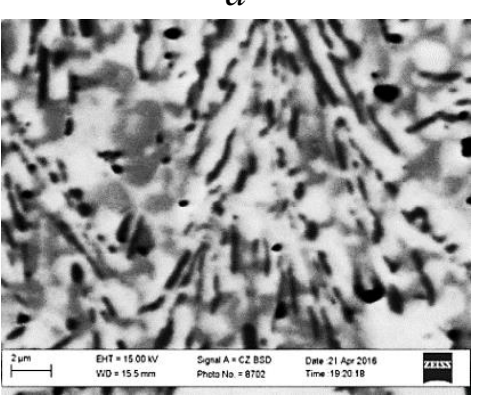

$d$

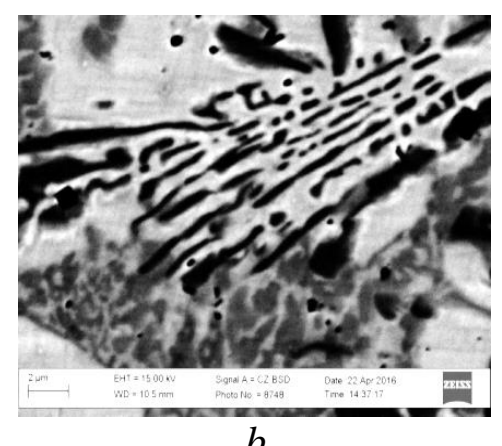

$b$

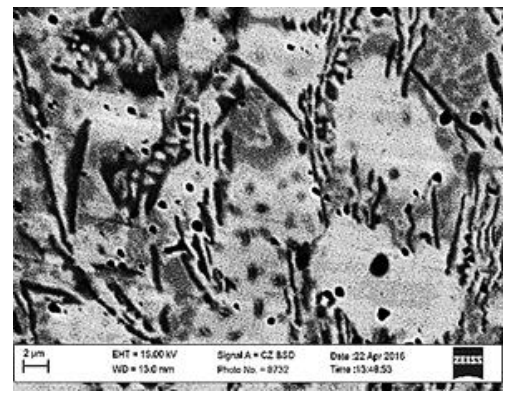

$e$

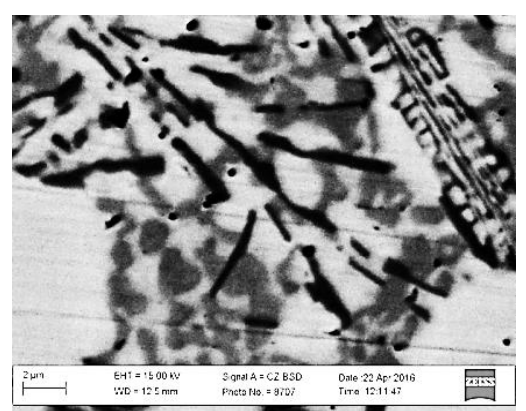

$c$

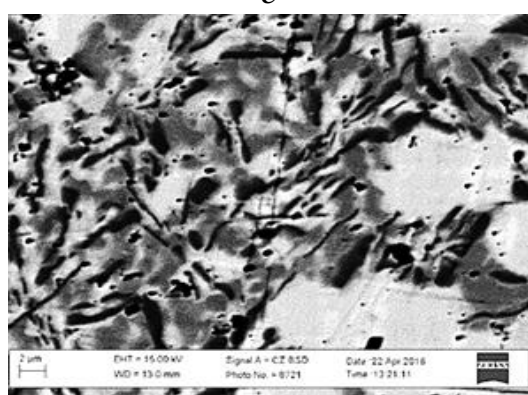

$f$

Fig. 9. Microstructure of metal deposited by melting of the CW 80Cr20B3Ti without adding $(a-d)$ and with the addition to its charge of AlMg $1(e)$ or $2(f)$ wt. \%, without $(a)$ and with horizontal vibration with an amplitude of $70(b), 200(c)$ and $300(d) \mu \mathrm{m}$ during deposition.

In particular, boride inclusions $(\mathrm{FeCr}) \mathrm{B},(\mathrm{FeCr})_{2} \mathrm{~B}$ shredded as much as possible under vibration with an amplitude of $300 \mu \mathrm{m}$ (Fig. $9 d$ ). The average size of inclusions in this case was from 1 to $20 \mu \mathrm{m}$ (Fig. $10 \mathrm{a}$ ). Surfacing using vibration of large parts or complex shape is much more difficult or is impossible. In this case, it was proposed to affect the microstructure of the deposited metal by adding AlMg powder in the amount of 1 or $2 \mathrm{wt} \%$ to the $\mathrm{CW}$ charge $80 \mathrm{Cr} 20 \mathrm{~B} 3 \mathrm{Ti}$.
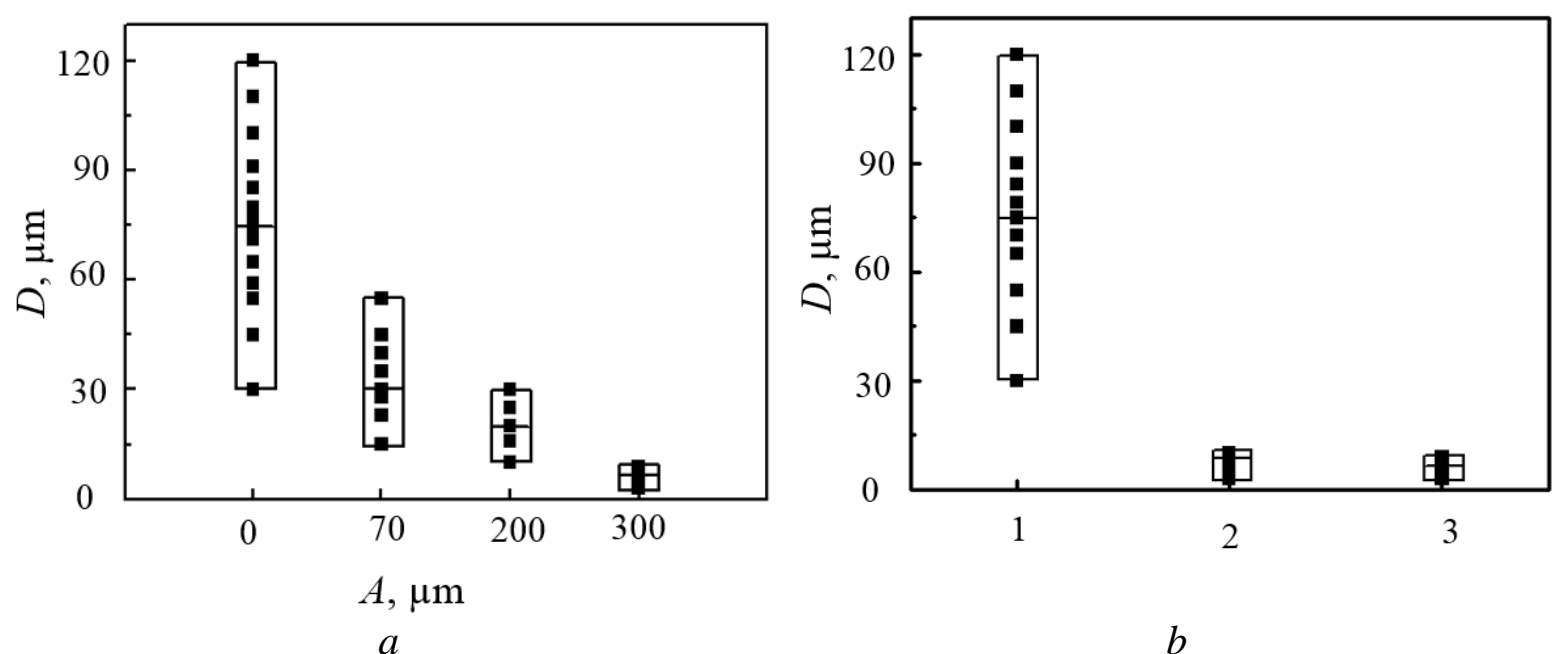

Fig. 10. Changes in the average sizes $\mathrm{D}$ of the $(\mathrm{FeCr}) \mathrm{B}$ and $(\mathrm{FeCr})_{2} \mathrm{~B}$ borides in the structure of the metal deposited by melting of the CW 80Cr20B3Ti, depending on the amplitude of the horizontal vibration $A(a)$ and the content of AlMg powder in the $\mathrm{CW}$ charge without using vibration during cladding $(b)$ : 1 - cladding by melting of the CW 80Cr20B3Ti of the base composition; 2, 3 - with the addition to the $\mathrm{CW}$ charge of the AlMg powder in the amount of 1 or 2 wt. $\%$. 


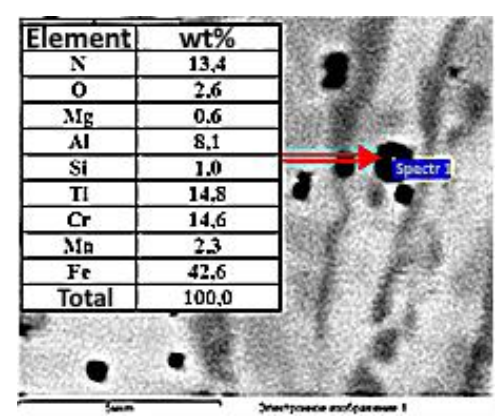

Fig. 11. Microstructure and elemental composition of metal cladded by melting of the CW 80Cr20B3 Ti with the addition to its charge of the $\mathrm{AlMg}$ powder in the amount of $2.0 \mathrm{wt}$ \%
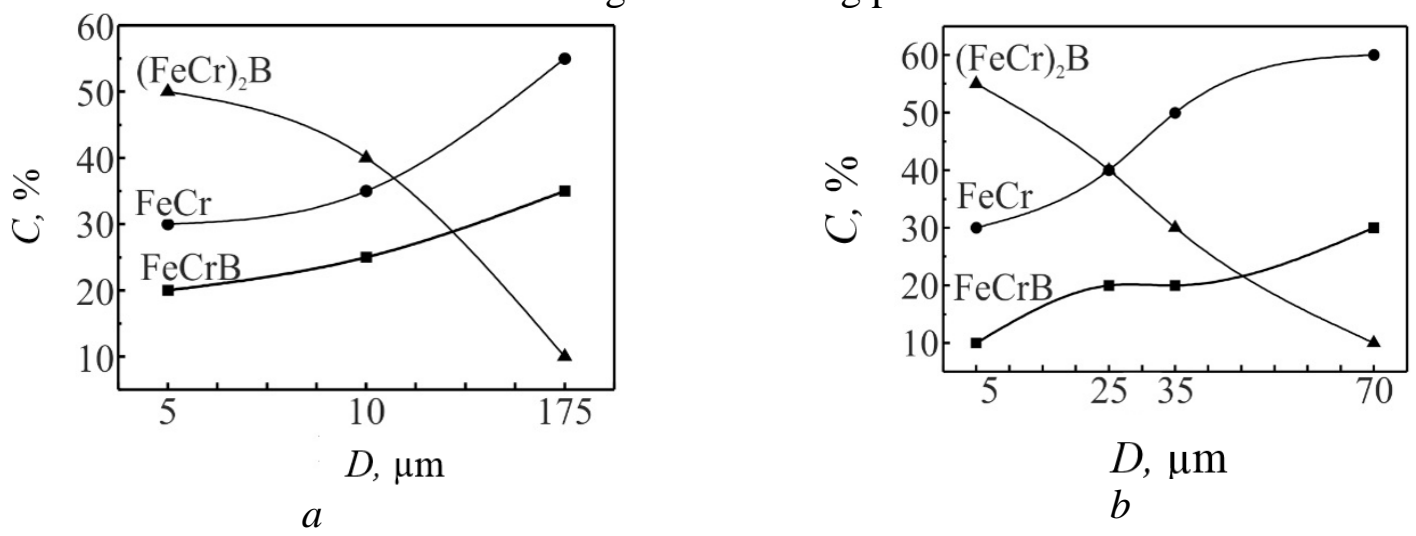

Fig. 12. Correlation between the portion $C$ of the phases as structural components and their average sizes $D$ in a metal deposited by melting of the CW Cr10B3Mn2Si $(a)$ or of the $\mathrm{CW}$ 80Cr20B3Ti (b).

Due to this, there are prerequisites for the oxidation reaction of magnesium located in the cavities of the $\mathrm{CW}$ charge, leading to the formation of dispersed particles of magnesium oxide, which serve as the centers of crystallization and growth of the number of grains from the melt of the cladded metal. In a metal deposited with CW 80Cr20B3Ti without adding AlMg powder, large needle-shaped borides $(\mathrm{FeCr}) \mathrm{B}$ and small ones $(\mathrm{FeCr})_{2} \mathrm{~B}$ are located on the background of austenitic matrix. The microstructure of metal deposited with $\mathrm{CW} 80 \mathrm{Cr} 20 \mathrm{~B} 3 \mathrm{Ti}$ on the base composition and with addition to the charge of AlMg powder was compared, and it was found that doping with magnesium contributes to the grinding of borides and their globulization (Fig. $9 e, f)$. Spectral analysis has determined that after adding the $\mathrm{AlMg}$ powder to the $\mathrm{CW}$ charge, the borides $(\mathrm{FeCr})_{2} \mathrm{~B}$ dominated in the microstructure of the deposited metal. In a metal deposited with $\mathrm{CW}$ 80Cr20B3 Ti on the base composition, the average size of borides was from 30 to $120 \mu \mathrm{m}$, but using $\mathrm{CW}$ with the addition of $\mathrm{AlMg}$ powder, their diameter has decreased by 8 times on the average (Fig. $5 \mathrm{~b}$ ). Due to the addition of AlMg powder to the $\mathrm{CW}$ charge 80Cr20B3 Ti, dispersed inclusions (up to $1 \mu \mathrm{m}$ ) of complexly doped nitrides were formed in the structure of the deposited layer. The X-ray spectral analysis determined the composition of the inclusions in the metal microstructure deposited with $\mathrm{CW} 80 \mathrm{Cr} 20 \mathrm{~B} 3 \mathrm{Ti}$ with the addition to its charge of AlMg powder in the amount of $2 \mathrm{wt}$. \% (Fig. 11). The average size of inclusions was from 0.1 to $0.5 \mu \mathrm{m}$.

The influence of vibration on the phase redistribution in the structure of the deposited layers has been revealed. In a metal deposited without vibration of $\mathrm{CW} \mathrm{Cr} 10 \mathrm{~B} 3 \mathrm{Mn} 2 \mathrm{Si}$, where the average size of boride inclusions was $175 \mu \mathrm{m}$, the phase ratio was: $(\mathrm{FeCr}) \mathrm{B} /(\mathrm{FeCr})_{2} \mathrm{~B}-4 / 1$. Due to the dispersion of boride inclusions (under the horizontal vibration of the substrate in the process of surfacing), the phase ratio has changed. In particular, to achieve the average boride size of $10 \mu \mathrm{m}$, the content of the $\mathrm{FeCr}_{2} \mathrm{~B}$ phase in the structure of the deposited metal was 
increased, and the phase ratio became $(\mathrm{FeCr}) \mathrm{B} /(\mathrm{FeCr})_{2} \mathrm{~B}-2.5 / 4$, but with the achievement of the maximum dispersion, when the average size of the $\mathrm{FeCr}_{2} \mathrm{~B}$ phase was $5 \mu \mathrm{m}$, the phase ratio changed: (FeCr)B/(FeCr) $)_{2} \mathrm{~B}-1 / 5$ (Fig. $12 a$ ).

Dispersion of boron inclusions, as well as phase redistribution due to vibration exposure in the process of cladding, was observed in the structure of metal deposited with CW 80Cr20B3Ti (Fig. $12 b$ ). In the original structure, the average size of boride inclusions and phase ratio were $70 \mu \mathrm{m}$ and $(\mathrm{FeCr}) \mathrm{B} /(\mathrm{FeCr})_{2} \mathrm{~B}-3 / 1$. For the maximum grinding of boride inclusions (with the average size of $5 \mu \mathrm{m})$, the hard phase $(\mathrm{FeCr}) \mathrm{B}$ portion decreased, while the portion of plastic phase $(\mathrm{FeCr})_{2} \mathrm{~B}$ increased $(\mathrm{FeCr}) \mathrm{B} /(\mathrm{FeCr})_{2} \mathrm{~B}-1 / 5$.

Cladding under vibration has increased the number of crystallization centers, which led to a redistribution of phases in the structure of the metal. During the crystallization of the metal melted without vibration, there were few centers of crystallization, i.e., conditions were created for the formation, in the first place, of boride inclusions $(\mathrm{FeCr}) \mathrm{B}$, which grow to large sizes. The content of chromium in boride inclusions $(\mathrm{FeCr}) \mathrm{B}$ reaches $18 \mathrm{wt} . \%$, and that of boron 10 wt. $\%$ at a simultaneous decrease of their content in the matrix to 4 wt. \%. During crystallization, under the effects of vibration, newly formed crystals of the first type are destroyed due to cavitation effects, forming a large number of new crystallization centers [1012]. This contributes to the formation, in the first place, of borides with lower boron content $(\mathrm{FeCr})_{2} \mathrm{~B}$. Smaller content of chromium ( $9 \mathrm{wt}$. \%) and boron $(6 \mathrm{wt} . \%)$ was needed to form such borides, which preconditions their greater amount.

\section{$4 \quad$ Mechanical characteristics of deposited layers}

The influence of vibration on the microhardness of a metal deposited with $\mathrm{CW}$ Cr10B3Mn2Si was evaluated across the welded rollers (Fig. 13). The average microhardness of the metal deposited without vibration reached $\sim 600 \mathrm{HV}$, while the average size of the boron phases was $175 \mu \mathrm{m}$ (Fig. 13, curve 1). As the amplitude of the vibration increases, the diameter of the boride inclusions decreases, which causes the growth of microhardness.

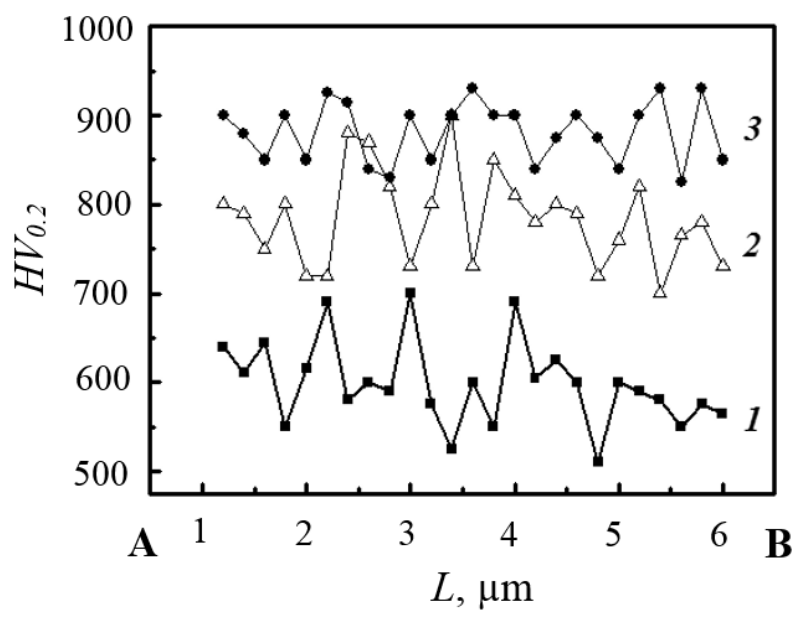

Fig. 13. Changing the microhardness of HV across the rollers of metal deposited by melting of the CW Cr10B3Mn2Si without (1) and with horizontal vibration with an amplitude of 70

(2) and 300 (3) $\mu \mathrm{m}$. $L$ - distance from the center of the roller A crest to the center of its overlap with adjacent roller B.

In particular, for the horizontal vibration of the substrate with an amplitude of $70 \mu \mathrm{m}$, when the average phase size is $10 \mu \mathrm{m}$, the average value of the microhardness of the deposited metal increased to $\sim 790 \mathrm{HV}$ (Fig. 13, curve 2). With an increase in the amplitude of vibration up to $300 \mu \mathrm{m}$, the average size of boride inclusions decreased to $5 \mu \mathrm{m}$, due to an increase in the 
average microhardness to $870 \mathrm{HV}$ (Fig. 13, curve 3). In general, the microhardness of the metal deposited with $\mathrm{CW}$ Cr10B3Mn2Si using the horizontal vibration of the substrate increased by 1.5 times. The micromechanical characteristics of the deposited metal were determined by the method of dynamic indentation and sclerometry. It was established that the Young's modulus of the metal deposited with CW Cr10B3Mn2Si without vibration was $271 \mathrm{GPa}$. In a metal deposited with a horizontal vibration with an amplitude of $300 \mu \mathrm{m}$, it has increased to $350 \mathrm{GPa}$. Thus, according to this indicator, the mechanical properties of the deposited metal have improved (the penetration depth of the indenter has decreased by $15 \%$, and the resistance of the material to penetration has increased by $20 \%$, as compared to the metal deposited without vibration). The average value of the microhardness of the metal deposited with $\mathrm{CW}$ 80Cr20B3Ti without vibration was $700 \mathrm{HV}$ (Fig. 14). When using horizontal vibration with an amplitude of $300 \mu \mathrm{m}$, microhardness has increased to $930 \mathrm{HV}$. At the same time, the scattering of values at amplitudes of 70 and $200 \mu \mathrm{m}$ remained significant. However, the horizontal vibration with the amplitude of $300 \mu \mathrm{m}$ lowered the scatter of microhardness values most significantly, which was associated with the maximum dispersion of structural components.

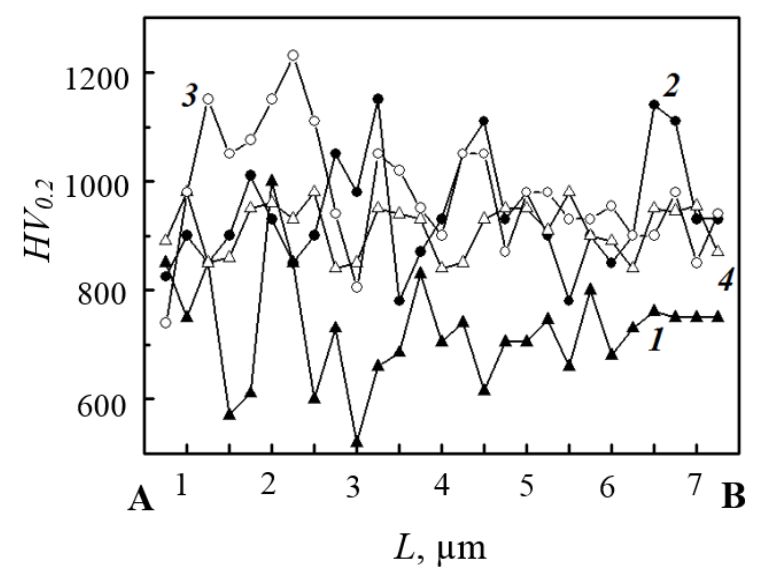

Fig. 14. The change in the microhardness $\mathrm{HV}$ of the deposited metal obtained by melting of the $\mathrm{CW}$

80Cr20B3Ti without using the vibration during cladding process (1) and using horizontal vibration with the amplitude of 70 (2), 200 (3) and 300 (4) $\mu \mathrm{m}$. $L$ - distance from the center of the roller A crest to the center of its overlap with adjacent roller B.

The Young's modulus of metal deposited with this CW increased from 310 (without vibration during cladding process) to $360 \mathrm{GPa}$ (using horizontal vibration with an amplitude of $300 \mu \mathrm{m})$. After adding AlMg powder to the CW charge with the basic composition, the characteristics of the deposited metal were improved. At the same time, the average value of the microhardness of metal increased from 700 to $850 \mathrm{HV}_{0.2}$, due to the formation of a significant number of complex doped high-hardness nitrides in its microstructure. Adding $\mathrm{AlMg}$ to the $\mathrm{CW}$ charge affects the structural and phase composition of the deposited layer, increases the compressive stresses of the second kind in the deposited metal from 281 to 378 $\mathrm{MPa}$, causes the shredding of borides $(\mathrm{FeCr}) \mathrm{B}, \mathrm{FeCr}_{2} \mathrm{~B}$, enhances the mechanical characteristics of the deposited metal (the Young's module has increaased by $15 \%$, and the resistance of the material to the penetration of the indenter has increased by $19 \%$ ).

\section{Wear resistance of deposited layers}

The durability of the deposited metal гтвук conditions of abrasive wear has been investigated, and mechanisms of damage occurrence in the deposited layers depending on the composition of the CW and the technology of surfacing have been revealed. In particular, the abrasive wear resistance of the layer deposited by a fixed abrasive increased by 2.5 times, and by a free abrasive by 2.3 times, under cyclic impact loading - by 2.8 times. An increase in the wear resistance of layers deposited under mechanical vibration is due to a significant reduction in the size of the disperse hardening phases (borides) and the change in their phase composition. In particular, with a decrease in the average size of boride inclusions from 175 to $5 \mu \mathrm{m}$, an 
increase in the compressive strength of the second kind occurs in the deposited layer, and its microhardness $\mathrm{HV}_{0.2}$ increased from 700 to 930 . With an increase in the phase content $(\mathrm{FeCr})_{2} \mathrm{~B}$ of the welded layer, the Young's modulus and resistance to brittle fracture increases, which also affects the wear resistance of the deposited layer (Table. 2).

Table 2. Relative wear resistance of metal deposited with CW Cr10B3Mn2Si under conditions of abrasive wear versus the deposited metal without vibration

\begin{tabular}{|c|c|c|c|}
\hline Cladding and wear conditions & $\begin{array}{c}\text { Without } \\
\text { vibration }\end{array}$ & \multicolumn{2}{|c|}{ With horizontal vibration } \\
\hline $\begin{array}{c}\text { Amplitude of mechanical oscillations, } \\
\mu \mathrm{m}\end{array}$ & - & 70 & 300 \\
\hline $\begin{array}{c}\text { Average size of borides, } \mu \mathrm{m} \\
\text { Fixed abrasive }\end{array}$ & 175 & 10.0 & 5.0 \\
\hline Free abrasive & 1 & 1.4 & 2.5 \\
\hline Impact wear & 1 & 2.5 & 2.3 \\
\hline Ratio of phases: $(\mathrm{FeCr}) \mathrm{B} /(\mathrm{FeCr})_{2} \mathrm{~B}$ & $4 / 1$ & $2.5 / 4$ & 2.8 \\
\hline
\end{tabular}

The nature of damage on the surface of the deposited layers after friction is in good agreement with the mass loss of specimens. On the worn-out surface of the metal deposited without vibration, there are deep, almost parallel grooves and traces of separated borides (FeCr)B (Fig. $15 a$ ). In the contact area of the metal deposited using horizontal vibration with an amplitude of $300 \mu \mathrm{m}$, there was practically no brittle fracture, since the amount of plastic phase increased $(\mathrm{FeCr})_{2} \mathrm{~B}$ (Fig. $15 \mathrm{~b}$ ). This is consistent with the morphology of the worn-out surface, on which no deep, small and evenly-spaced scratches were found [13-15].

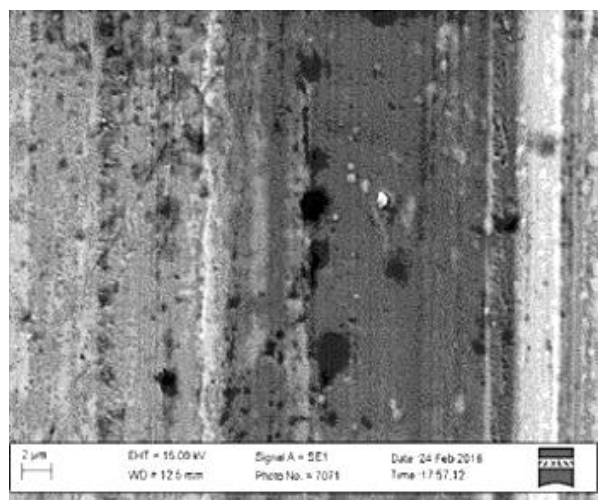

$a$

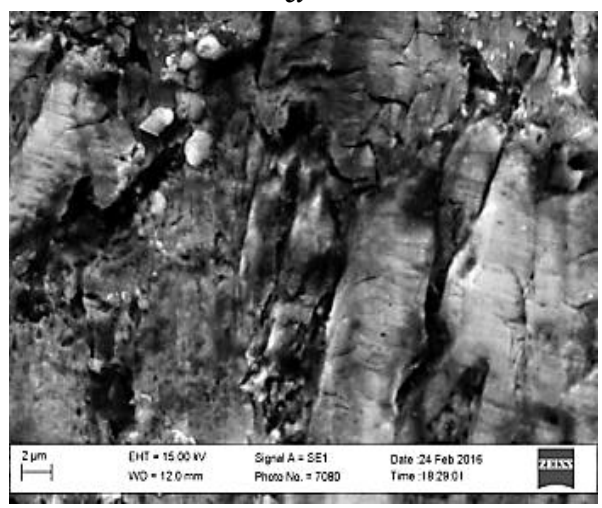

$c$

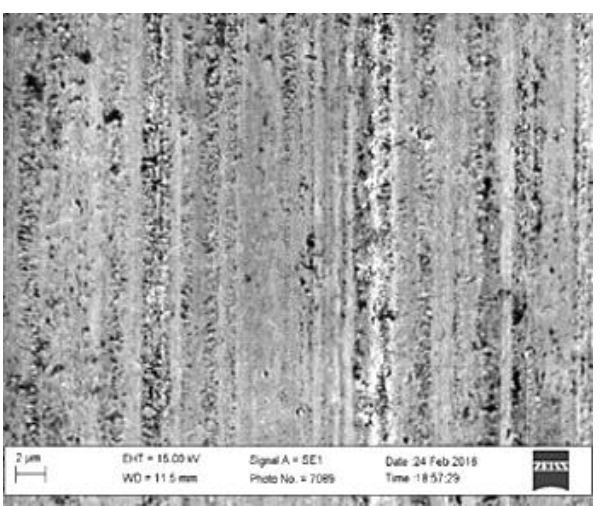

$b$

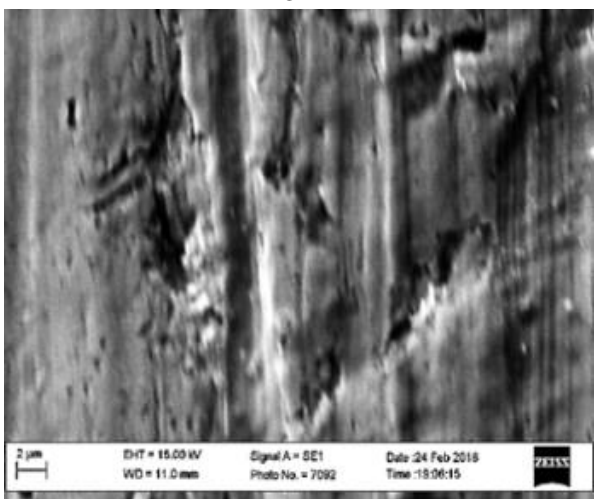

$d$

Fig. 15. Morphological features of worn-out surfaces deposited with CW Cr10B3Mn2Si without $(a, c)$ and with horizontal $(b, d)$ vibration with an amplitude of $300 \mu \mathrm{m}$ after wear tests with fixed $(a, b)$ and free $(c, d)$ abrasive. 
For fixed abrasive wear of the metal welded without vibration, the main mechanism of wear is separation of solid borides (FeCr)B (Fig. 15 c). Moreover, a free abrasive material enhances separation. For surfacing with the use of horizontal vibration, there were small plastic inclusion of borides $(\mathrm{FeCr})_{2} \mathrm{~B}$ in the structure of the metal. Therefore, their separation from the ferrite matrix was complicated. As a result, the wear of the welded metal has also decreased, and only shallow grooves were observed on the wear surface (Fig. $15 d$ ).

The nature of damage to the deposited metal surface under impact loading was analyzed on the roller crests and in the area of their overlap with adjacent beaded welds. In a metal deposited on roller crests without vibration, high density damage was detected (Fig. $16 a$ ). Damage to the roller crests began with plastic deformation, breaking of cohesive bonds between solid borides and a more plastic matrix, followed by the first extraction of large and then smaller metal borides due to their insufficient adhesion to the matrix [16-18]. In the area of overlapping, roller crests damaged areas that increased in size, and the deposited metal was damaged due to cracking of the borides (Fig. $16 b$ ).

Using horizontal vibration with the amplitude of $300 \mu \mathrm{m}$, the phase correlation and morphology of the structural components of the deposited layer have changed. A structurephase composition of this type caused qualitative changes in the nature of the effect that occurred under impact loading. The main factor of the metal wear on the roller crests and in the area of their overlap is the ability of the cladded layer to deform plastically and thereby relax the stresses that arise during the impact wear test $[1,10]$. It is inherent in the metal on the roller crests and in the area of their overlap and is associated with the highest dispersion of the plastic phase of $(\mathrm{FeCr})_{2} \mathrm{~B}$. It was also noted that the lowest (from all analyzed variants of the deposited layers) cracking tendency of the deposited layers is with using horizontal vibration (Fig. $16 b$ ).

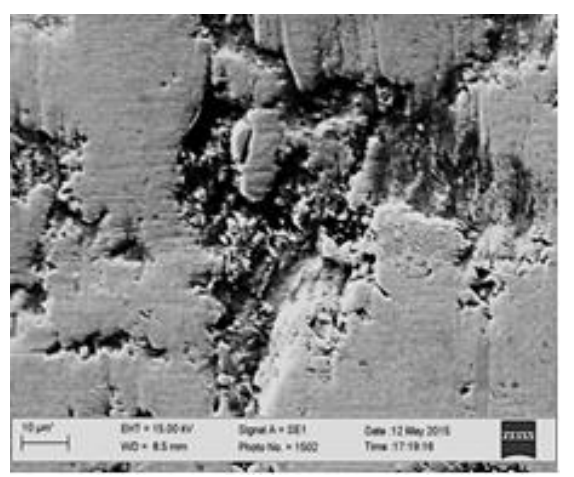

$a$

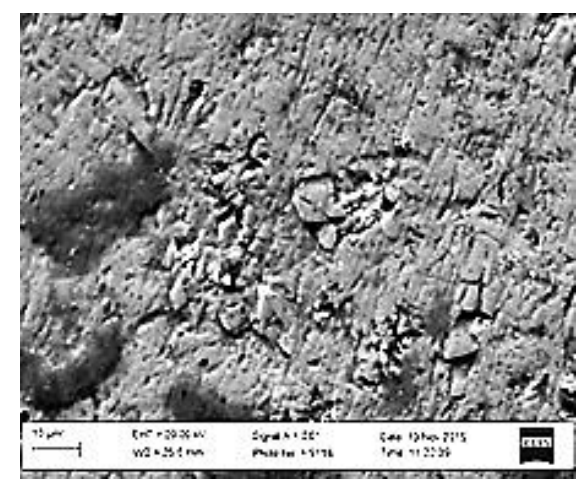

$b$

Fig. 16. Morphology of damages caused by wear during impact wear test of metal deposited with CW Cr10B3Mn2Si without vibration $(a)$, using horizontal vibration with an amplitude of $300 \mu \mathrm{m}(b)$.

The vibration overlay during the metal surfacing with CW 80Cr20B3Ti, as well as for the metal deposited with $\mathrm{CW}$ Cr10B3Mn2Si, also leads to a significant reduction in the average size of boride inclusions, and, as a consequence, increases its wear resistance (Table 3). In particular, with a decrease in the average size of boride inclusions from 70 to $5 \mu \mathrm{m}$ under conditions of wear with fixed and free abrasive material, wear resistance of the deposited metal increases by 1.7 times, and in case of wear under cyclic impact loading it increases by 2 times. The morphology of damage on the surface under such wear conditions was analyzed, and the elements of brittle microcracking of the metal welded without vibration were found. (Fig. 17 a). No substantial separation zones were found that were associated with high plasticity of the austenitic matrix and the presence of a reinforcing plastic phase $(\mathrm{FeCr})_{2} \mathrm{~B}$. In a metal deposited using horizontal vibration, signs of plastic deformation were found after abrasive wear (Fig. 17 $b$ ). Damage to the deposited metal occurred by detaching the surface layer of oxides. 
Table 3. Relative wear resistance of metal deposited with CW 80X20P3T versus metal deposited without vibration

\begin{tabular}{|c|c|c|c|c|}
\hline \multirow{2}{*}{ Type of wear } & \multirow{2}{*}{$\begin{array}{c}\text { Without } \\
\text { vibration }\end{array}$} & \multicolumn{3}{|c|}{\begin{tabular}{c} 
Horizontal vibration at amplitude, \\
\cline { 3 - 5 }
\end{tabular}} \\
\cline { 3 - 5 } & & 70 & 200 & 300 \\
\hline Average size of borides, $\mu \mathrm{m}$ & 70 & 35 & 25 & 5 \\
\hline Fixed abrasive & 1 & 0.9 & 1.2 & 1.7 \\
\hline Free abrasive & 1 & 1.3 & 1.5 & 1.7 \\
\hline Impact wear & 1 & 1 & 1.3 & 2 \\
\hline $\begin{array}{c}\text { Ratio of phases } \\
(\mathrm{FeCr}) \mathrm{B} /(\mathrm{FeCr})_{2} \mathrm{~B}\end{array}$ & $3 / 1$ & $3 / 2$ & $2 / 4$ & $1 / 5$ \\
\hline
\end{tabular}

The damage mechanism of the metal surface deposited with CW 80Cr20B3Ti with the addition of $1 \mathrm{wt}$. \% of AlMg to its charge during abrasion wear test also changed from brittle to plastic $($ Fig. $17 c)$.

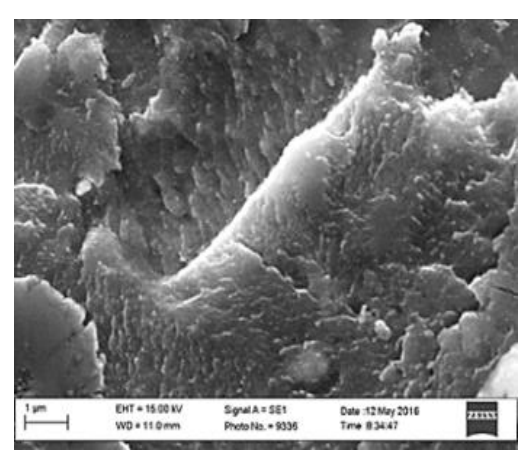

$a$

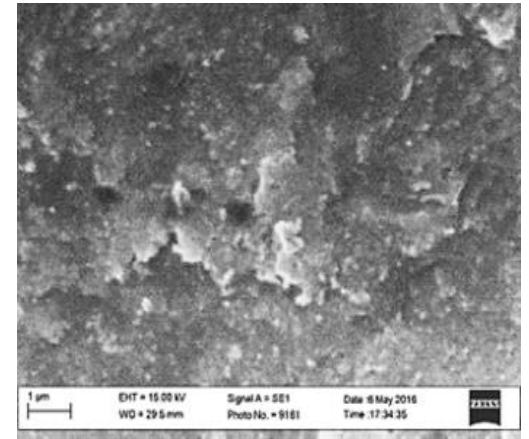

$b$

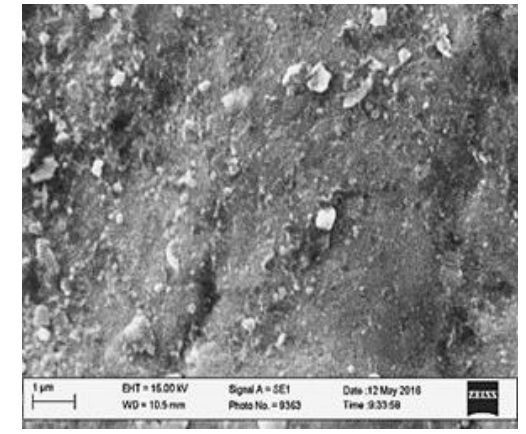

$c$

Fig. 17. Morphology of the cladding surface after impact wear of metal deposited by melting of the CW 80Cr20B3Ti without $(a)$ and with horizontal vibration with an amplitude of $300 \mu \mathrm{m}(b)$, and of the CW 80Cr20B3Ti with addition to its charge of the AlMg powder in the amount of $1 \mathrm{wt} . \%(c)$.

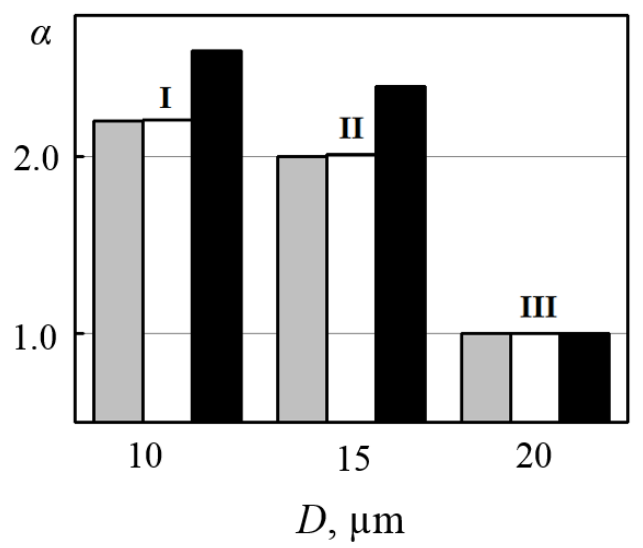

Fig. 18. Relative (compared to the initial deposited metal) wear resistance $\alpha$ versus the average size of the borides $D$ in the cladding metal obtained by melting of the $\mathrm{CW}$ 80Cr20B3 Ti with addition to the $\mathrm{CW}$ charge of the base composition the AlMg powder in the amount of 1 (I) or 2 (II) wt. \% or without it (III), during wear test with fixed (1), free abrasive (2) and under the impact wear (3).

Adding AlMg powder in the amount of $1 \mathrm{wt}$. \% to the charge of $\mathrm{CW} 80 \mathrm{Cr} 20 \mathrm{~B} 3 \mathrm{Ti}$ increases the wear resistance of the welded metal by 1.6 times in case of wear with a fixed and free abrasive material; in case of wear under the action of cyclic impact load, wear resistance 
increased by 1.8 times compared to the metal deposited with the $\mathrm{CW}$ base composition (Fig. 18). This increase is due to an increase in the hardness of the deposited layer as a result of the reinforcing boride phase dispersion due to the additional allocation of fine-dispersed doped nitrides in the structure of the deposited layer.

\section{CONCLUSION}

It is established that the vibration of the part during its surfacing results in the dispersion of the structure of the deposited metal, which depends on the parameters of the oscillations. Due to horizontal vibration with an amplitude of $300 \mu \mathrm{m}$, the average size of individual boron inclusions is reduced from $250-300$ to $4-5 \mu \mathrm{m}$.

Mechanical vibration contributes to phase redistribution during surfacing, which increases the microhardness of the deposited metal from 600 to $870 \mathrm{HV}$ for horizontal vibration, and phases are evenly distributed over the surface of the weld metal.

Deposited layers obtained by horizontal vibration showed an increased (2.3-2.5 times) abrasive resistance in the process of wear test with a fixed and free abrasive compared to a layer deposited without vibration. The features of the wear mechanism are revealed, according to which an increase in wear resistance of the layer prepared by using vibration was associated with a smaller number of grooves on the worn-out surface due to the separation of boron inclusions. It is established that vibration during layer surfacing increases (by 1.8 times) their stability under cyclic impact wear. This is achieved by the ability of the welded metal to deform plastically and thus relax tensile stresses.

It was found that the addition of AlMg powder (1 wt. \%) to the CW charge of the base system $\mathrm{Fe}-\mathrm{Cr}-\mathrm{B}-\mathrm{C}$ contributes to reducing the inclusions of borides in the deposited metal (up to 7 times).

It was established that the AlMg powder in the CW charge 80Cr20B3Ti contributes to the allocation of dispersed (not more than $1 \mu \mathrm{m}$ ) inclusions of complexly nitrides, which significantly increase the microhardness (1.2 times) and, respectively, wear resistance (1.5 times) of the deposited layers, and the wear mechanisms has changed from brittle to plastic.

\section{REFERENCES}

[1] Brezinová, J., Viňáš, J., Maruschak, P. O., Guzanová, A., Draganovská, D., Vrabel', M. "Sustainable renovation within metallurgical production", RAM-Verlag, Lüdenscheid, Germany, p. 215, 2017.

[2] Yuksel, N., Sahin, S. "Wear behavior-hardness-microstructure relation of $\mathrm{Fe}-\mathrm{Cr}-\mathrm{C}$ and $\mathrm{Fe}-\mathrm{Cr}-\mathrm{C}-\mathrm{B}$ based hardfacing alloys“, Mater. Design 58, pp. 491 - 498, 2014.

[3] Sorour, A., Chromik, R., Gauvin, I. H., Brochu, M. "Understanding the solidification and microstructure evolution during CSC-MIG welding of $\mathrm{Fe}-\mathrm{Cr}-\mathrm{B}$-based alloy", Mater. Character. 86, pp. 127 - 138, 2013.

[4] Wanga S., Li, H., Chenb, X., Chia, J., Li, M., Cha, L., Xua, H. “Improving microstructure and wear resistance of plasma clad Fe-based alloy coating by a mechanical vibration technique during cladding”, Mater. Sci. Eng. A 528, pp. 397 - 401, 2010.

[5] Pul'ka, Ch. V., Shablyy, O. N., Senchyshyn, V. S., Sharik, M. V., Hordan, H. N. "Influence of vibrations of a workpiece in the course of fusion on a structure and properties of the metal", Avtomat. Svarka 705, pp. 27 - 29, 2012. 
[6] Voitovych, A. A., Pokhmurs'ka, H. V., Student, M. M., Student, O. Z. "Specific features of the formation and fracture of fused layers from flux-core wires of the $\mathrm{Fe}-\mathrm{Cr}-\mathrm{B}-\mathrm{C}$ system under impact loads", Probl. Trybol. 4, pp. 114 - 123, 2015.

[7] Pokhmurs'ka, H. V., Student, M. M., Lanets', O. S., Voitovych, A. A. "Influence of vibration in the course of surfacing of a protective layer on its microstructure and impactabrasive wear", Materials Science 51, pp. 412 - 417, 2015.

[8] Voitovych, A. A., Pokhmurs'ka, H. V., Student, M. M., Student, O. Z. "Microstructure and abrasive-wear resistance of the vibration-deposited metal of core wires of the basic Fe-Cr-B system”, Materials Science 52, pp. 365 - 370, 2016.

[9] Pokhmurs'ka, H. V., Student, M. M., Dzyubyk, A. R., Voitovych, A. A., Khlopyk, O. P. "Corrosion resistance of the metal vibration deposited from flux-core wires based on the FE-CR-B system”, Materials Science 52, pp. 694 - 699, 2017.

[10] Brezinova, J., Guzanova, A., Maruschak, P., Lorincova, D. "Study of wear processes of weld clads”, Acta Metall. Slovaca 20, pp. 167 - 176, 2014. DOI: 10.12776/ams.v20i2.293

[11] Brezinová, J., Guzanová, A., Draganovská, D., Maruschak, P., Landová, M. "Study of selected properties of thermally sprayed coatings containing WC and WB hard particles", Acta Mech. Autom 10, pp. 296 - 299, 2016. DOI:10.1515/ama-2016-0046

[12] Guzanová, A., Brezinová, J., Bronček, J., Maruschak, P., Landová, M. "Study of selected properties of coatings devoted to extreme tribo-corrosive conditions", Materials Science Forum 818, pp. 32 - 36, 2015. DOI: 10.4028/www.scientific.net/MSF.818.32

[13] Moiseenko, D. D., Maksimov, P. V., Panin, S. V., Babich, D. S., Panin, V. E. "Defect Accumulation in Nanoporous Wear-Resistant Coatings Under Collective Recrystallization: Simulation by Hybrid Cellular Automaton Method", In: Hsueh C. H. et al. (eds) Handbook of Mechanics of Materials, Springer, Singapore, pp. 1 - 35, 2018. DOI: 10.1007/978-981-10-6855-3_72-1

[14] Panin, S., Vlasov, I., Dudina, D., Ulianitsky, V., Stankevich, R., Batraev, I., Berto, F. "Mechanical characterization of composite coatings formed by reactive detonation spraying of titanium”, Metals 7 (9), 355, 2017. DOI: 10.3390/met7090355

[15] Balokhonov, R. R., Panin, S. V., Romanova, V. A., Schmauder, S., Makarov, P. V. "Numerical simulation of deformation and fracture in low-carbon steel coated by diffusion borating", Theoretical and Applied Fracture Mechanics 41, pp. 9 - 14, 2004. DOI: $10.1016 / j . t a f m e c .2003 .11 .002$

[16] Šofer, M., Fajkoš, R., Halama, R. "Influence of induction hardening on wear resistance in case of rolling contact", Journal of Mechanical Engineering - Strojnícky časopis 66 (1), pp. 17 - 26, 2016. DOI: 10.1515/scjme-2016-0007

[17] Handa, A., Chawla, V. "Experimental evaluation of mechanical properties of friction welded dissimilar steels under varying axial pressures", Journal of Mechanical Engineering - Strojnícky časopis 66 (1), pp. 27 - 36, 2016. DOI: 10.1515/scjme-20160008

[18] Kindrachuk, M. V., Dushek, Yu. Ya., Luchka, M. V., Gladchenko, A. N. "Evolution of the structure and properties of eutectic coatings during friction", Powder Metallurgy and Metal Ceramics 34, pp. 321 - 326, 1995. DOI: 10.1007/BF00560139 